\title{
Personality and the Subjective Effects of Acute Amphetamine in Healthy Volunteers
}

\author{
Tara L White*, , David C Lott ${ }^{2,3}$ and Harriet de Wit ${ }^{2}$ \\ 'Department of Psychiatry and Human Behavior, Center for Alcohol and Addiction Studies, Brown University, Providence, RI, USA; ${ }^{2}$ Department \\ of Psychiatry, The University of Chicago, Chicago, IL, USA; ${ }^{3}$ Department of Psychiatry, The University of Illinois at Chicago, Chicago, IL, USA
}

\begin{abstract}
Individual differences in the positive mood and other subjective effects of $d$-amphetamine have been linked to personality traits related to sensation seeking. The current study extends these associations to separate personality traits of reward sensitivity, physical fearlessness, and impulsivity. A total of 128 healthy volunteers received oral doses of $d$-amphetamine $(10$ and $20 \mathrm{mg}$ ) or placebo in counterbalanced order. Their responses to the drug were measured using the Profile of Mood States, Addiction Research Center Inventory, and Drug Effects Questionnaire. Participants completed the Multidimensional Personality Questionnaire Brief Form to assess personality traits related to reward sensitivity (Agentic Positive Emotionality and Social Potency (SP)), physical fear (Harm Avoidance (HA)), and impulsivity (Control $(\mathrm{CL})$ ). Participants were rank ordered on each trait, and individuals with scores in the top and bottom thirds of scores on each trait were compared using ANCOVA. High trait physical fearlessness (low HA) was associated with greater positive activational effects of $10 \mathrm{mg}$-amphetamine. High trait reward sensitivity (high SP) was marginally associated with greater positive activational effects of $20 \mathrm{mg}$ d-amphetamine. High trait impulsivity (low $\mathrm{CL}$ ) was unrelated to positive drug effects in response either dose. The two separate personality traits of physical fearlessness and reward sensitivity are associated with $d$-amphetamine effects on mood in healthy volunteers. Implications for the vulnerability to psychostimulant addiction in healthy nonaddicts are discussed. Neuropsychopharmacology (2006) 31, 1064-1074. doi:I0.1038/sj.npp.1300939; published online 19 October 2005
\end{abstract}

Keywords: monoamine; emotion; impulsivity; human; drug effects; personality

\section{INTRODUCTION}

The acute effects of $d$-amphetamine on measures such as elation, euphoria, and excitation vary across individuals (de Wit et al, 1986; Silberman et al, 1981; Nurnberger et al, 1982). Individual differences in the magnitude of the drug effect have been reported, on measures such as self-reports of control, friendliness, and arousal, and physician-rated elation (Crabbe et al, 1983; Silberman et al, 1981). Individual differences in the direction or quality of the effects of the drug have also been reported, including, for example, either increases or decreases in observer-rated excitation, self-rated tension, and fMRI measures of prefrontal cortex efficiency (Nurnberger et al, 1982; Crabbe et al, 1983; Mattay et al, 2003). Causes of such betweensubjects differences are not well understood. However, commonalities exist between the neurochemical mecha-

\footnotetext{
*Correspondence: Dr TL White, Department of Psychiatry and Human Behavior, Center for Alcohol and Addiction Studies, Brown University, 345 Blackstone Blvd, Box G-BH, Providence, RI 02912, USA, Tel: + | 40 I 444 1893, Fax: + | 40 | 444 188|,

E-mail: Tara_White@Brown.edu

Received 24 March 2005; revised 25 August 2005; accepted 7 September 2005

Online publication: 14 September 2005 at http://www.acnp.org/ citations/Npp09|405050197/default.pdf
}

nisms of direct drug effects and the apparent neurobiological basis of personality traits, suggesting that individual differences in responses to stimulant drugs may relate systematically to individual differences in personality among other factors (for example, see Mattay et al, 2003; Reif and Lesch, 2003).

To date, most studies examining associations between personality and $d$-amphetamine effects have focused on the personality traits of Tridimensional Personality Questionnaire (TPQ) Novelty Seeking, SSS-V sensation seeking, and Eysenck Personality Questionnaire Psychoticism (EPQ-P), and have produced inconsistent results (Table 1). For instance, TPQ Novelty Seeking was positively associated with subjective stimulation in one study (Hutchison et al, 1999), and with elevated mood in another (Sax and Strakowski, 1998), but TPQ scores were unrelated to $d$-amphetamine effects in a third (Corr and Kumari, 2000). SSS-Form V sensation seeking was positively associated with subjective stimulation, elation, vigor, and positive mood effects of $d$-amphetamine in one study (eg Hutchison et al, 1999), but were unrelated in others (eg Alessi et al, 2003; Chait, 1993; de Wit et al, 1986). In another study, EPQ-P, a measure of fearless impulsivity associated with sensation seeking, was not associated with energetic arousal ratings in participants who received 5 or $10 \mathrm{mg} d$ amphetamine, but was positively associated with energetic 
Table I Personality Investigations of Positive Subjective Responses to d-Amphetamine

Findings

\begin{tabular}{|c|c|c|c|c|c|c|c|c|}
\hline & & & & & $\begin{array}{l}\text { EPQI } \\
\text { EPI }\end{array}$ & TPQ & & \\
\hline Authors & $N$ & d-Amphetamine dose & Personality measures & sss & $\mathbf{P}$ & NS & Details & \\
\hline Alessi et al (2003) & $24(16)$ & $0,5,10,20 \mathrm{mg}$ p.o. ${ }^{a}$ & SSS Form V (Zuckerman et al, 1978) & n.s. & & & $\begin{array}{l}\text { SSS scales unrelated to HR, LR groupings, mood/ } \\
\text { subjective effects on POMS, ARCI, VAS measures }\end{array}$ & \\
\hline $\begin{array}{l}\text { Corr and Kumari } \\
(2000)\end{array}$ & $63(31)$ & 0, 5, $10 \mathrm{mg}$ p.o. & $\begin{array}{l}\text { Eysenck Personality Questionnaire (EPQ; Eysenck and } \\
\text { Eysenck, 1975); Tridimensional Personality Questionnaire } \\
\text { (TPQ; Cloninger, 1989) }\end{array}$ & &,-+ & n.s. & $\begin{array}{l}\text { High EPQ-Psychoticism Ss: Amphetamine group reported } \\
\text { decreased energetic arousal, increased tense arousal, and } \\
\text { decreased hedonic tone compared to placebo group on } \\
\text { UWIST Mood Adjective Checklist (UMACL); TPQ } \\
\text { Novelty Seeking, EPQ-Extraversion unrelated to } \\
\text { amphetamine effects on UMACL }\end{array}$ & \\
\hline Hutchison et al (1999) & $36(18)$ & $0,20 \mathrm{mg}$ p.o. ${ }^{\mathrm{a}}$ & $\begin{array}{l}\text { SSS Form V (Zuckerman et al, 1978); TPQ Version } 4 \\
\text { (Cloninger, 1987) }\end{array}$ & + & & + & $\begin{array}{l}\text { TPQ Novelty Seeking } r=0.46, p<0.05 \text { with subjective } \\
\text { stimulation (BAES); SSS-V ES, Dis, BS r's }=0.42,0.49,0.46 \text {, } \\
p<0.05 \text { with BAES Stimulation; SSS-V Dis } r=0.45,0.45 \text {, } \\
0.41 \text { with POMS Elation, Vigor, Positive Mood, } p<0.05\end{array}$ & \\
\hline $\begin{array}{l}\text { Sax and Strakowski } \\
\text { (1998) }\end{array}$ & $11(6)$ & $0,0.25 \mathrm{mg} / \mathrm{kg}$ p.o. ${ }^{\mathrm{a}}$ & TPQ Version 4 (Cloninger, 1987) & & & + & $\begin{array}{l}\text { TPQ Novelty Seeking } r=0.73, p<0.01 \text { with increase in } \\
\text { behavioral ratings of elevated mood response to three } \\
\text { doses }\end{array}$ & 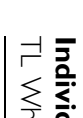 \\
\hline Chait (1993) & $29(13)$ & $0,7.5-20 \mathrm{mg}^{\mathrm{a}, \mathrm{c}}$ & $\begin{array}{l}\text { SSS Form V (Zuckerman et al, 1978); Eysenck Personality } \\
\text { Inventory (EPI; Eysenck and Eysenck, I 968); TPQ Version } \\
4 \text { (Cloninger, 1987); Drug Attitudes Scale (DAS; } \\
\text { Goodstadt et al, 1978); 'morningness' questionnaire } \\
\text { (Smith et al, 1989) }\end{array}$ & n.r. & n.r. & n.r. & $\begin{array}{l}\text { Higher Speed scale scores (positive attitude toward } \\
\text { amphetamines) on Drug Attitudes Scale in amphetamine } \\
\text { choosers, } p<0.05 \text {; no associations reported between EPI, } \\
\text { SSS-V, TPQ scores and POMS, ARCI, VAS ratings of drug } \\
\text { effects }\end{array}$ & 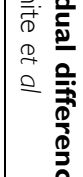 \\
\hline de Wit et al (1986) & 31 & $0,5 \mathrm{mg}$ p.o., ${ }^{\mathrm{a}, \mathrm{c}, \mathrm{d}}$ & $\begin{array}{l}\text { Sensation Seeking Scale (Total; Zuckerman, 1971); Rotter } \\
\text { Internal/Extfernal Locus of Control (Rotter, 1966); TMAS } \\
\text { (Taylor, 1953); Psychopathic State Inventory (Haertzen } \\
\text { et al, 1980) }\end{array}$ & n.s. & & & $\begin{array}{l}\text { Amphetamine choosers and non-choosers differed in } \\
\text { mood responses to amphetamine, but did not differ on } \\
\text { any personality trait, with the exception of greater PSI } \\
\text { 'Search for High' scores in amphetamine choosers }\end{array}$ & 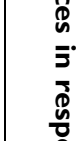 \\
\hline Uhlenhuth et al (198I) & $45(16)$ & $0,5 \mathrm{mg}$ p.o. ${ }^{\mathrm{a}, \mathrm{c}}$ & $\begin{array}{l}\text { EPI (Eysenck and Eysenck, 1968); Jackson Personality } \\
\text { Research Form (Jackson, 1974); Bass Acquiescence Scale } \\
\text { (Bass, 1956); Group Embedded-Figures Test (Witkin et al, } \\
\text { 197I) }\end{array}$ & & n.r. & & $\begin{array}{l}\text { No associations reported between personality and } \\
\text { amphetamine effects on POMS mood ratings }\end{array}$ & 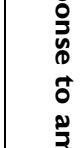 \\
\hline
\end{tabular}


arousal in another group of participants administered placebo. The data also suggested that EPQ-P may be associated with aversive, rather than pleasurable, responses to amphetamine (tense arousal; Corr and Kumari, 2000). Thus, while the personality measures of sensation seeking, novelty seeking, and psychoticism appear to be linked to individual differences in responses to $d$-amphetamine, the precise relationship between these personality traits and $d$-amphetamine responses remains unclear.

One factor that may contribute to these inconsistencies is the fact that sensation seeking is a complex personality dimension, which appears to involve several conceptually distinct emotional tendencies. Sensation seeking may include the tendency to respond strongly to external rewards, the tendency to fearlessly approach potentially harmful situations, and the tendency to act impulsively (Campbell and Heller, 1987; Zuckerman, 1989, 1993; Glicksohn and Abulafia, 1998). These specific tendencies can be measured separately by other personality scales. For example, the TPQ Reward Dependence (Cloninger, 1986), Extraversion (Lucas et al, 2000), and Multidimensional Personality Questionnaire (MPQ) and the MPQ Brief Form (MPQ-BF) Positive Emotionality scales (Tellegen, 1982; Patrick et al, 2002; Depue and Collins, 1999) are particularly well suited to assess sensitivity to reward. The MPQ and MPQ-BF Harm Avoidance scales are sensitive to the tendency to engage in potentially harmful behaviors (Tellegen, 1982; Patrick et al, 2002), and the TPQ Novelty Seeking (Cloninger, 1986), EPI Impulsivity, EPQ-P (Acton, 2003), MPQ Constraint, MPQ Control (Tellegen, 1982; Patrick et al, 2002), and P-ImpUSS scales (Zuckerman, 1989) can provide specific measures of impulsivity. Measures of each of these three dimensions correlate with self-reported sensation seeking (Zuckerman, 1989; Depue and Collins, 1999; Patrick et al, 2002; Campbell and Heller, 1987).

Tellegen's MPQ (and the shortened version MPQ-BF) has been empirically derived to provide orthogonal, relatively uncorrelated scales for the three traits in question (Tellegen, 1982; Patrick et al, 2002). This feature suggests that this questionnaire may be useful to examine the relations between the specific traits and responses to drugs. Several previous studies have examined MPQ scores in relation to acute drug responses, including bromocriptine (Depue et al, 1994), methylphenidate (Morrone-Strupinsky, 2002), and phenylephrine (White and Depue, 1999), and in relation to long-term drug use (methamphetamine; Goldstein et al, 2002). High scores on the MPQ factor of Positive Emotionality, which measures the personality dimension of reward sensitivity (Depue and Collins, 1999; Lucas et al, 2000), have been linked to greater eyeblink and prolactin responses to the dopamine D2 agonist bromocriptine (Depue et $a l, 1994)$ and greater growth hormone and contextual cue responses to methylphenidate (MorroneStrupinsky, 2002). Low scores on the MPQ scale of Harm Avoidance, which measures the personality dimension of physical fear, have been associated with greater ocular dilator muscle response to the noradrenergic agonist phenylephrine (White and Depue, 1999) and with lowered orbitofrontal gyrus metabolism in recently abstinent, methamphetamine-dependent individuals (Goldstein et al, 2002). Other measures of impulsive behavior, which are likely associated with the MPQ-BF Control scale, have been shown to be associated with low cortisol and prolactin responses to the serotonergic agents paroxetine and fenfluramine (Reist et al, 1996; Coccaro et al, 1997).

The current study used the Brief Form of the MPQ to investigate the association between these three traits of reward sensitivity, physical fearlessness, and impulsivity in relation to responses to $d$-amphetamine (10 and $20 \mathrm{mg}$ ) in healthy volunteers. This study extends the previous studies by examining four specific personality-drug response relationships. First, MPQ-BF measures of reward sensitivity (ie Agentic Positive Emotionality, Social Potency scales) were expected to be positively associated with the positive activational effects of amphetamine. Second, MPQ-BF measures of physical fear (ie Harm Avoidance scale) were expected to be negatively associated with the positive activational effects of amphetamine. Third, MPQ-BF measures of low impulsivity (ie Control scale) were expected to be negatively associated with the positive subjective and mood effects of amphetamine. Amphetamine responses were expected to be unrelated to scores on other personality measures (eg Social Closeness, Stress Reaction, Absorption scales), which are orthogonal to these three traits.

The overarching goal of the current study was to use the MPQ-BF to clarify the specific personality correlates of $d$-amphetamine effects previously associated with sensation seeking, using orthogonal measures of the personality traits related to reward sensitivity, physical fearlessness, and impulsivity and several potentially discriminant traits in healthy volunteers. The doses of 10 and $20 \mathrm{mg}$ were selected because they are safe and have been well characterized in healthy volunteers. The relatively low, 10-mg dose in particular was expected to provide a good measure of sensitivity to the drug's effects.

\section{MATERIALS AND METHODS}

\section{Participants}

Healthy volunteers $(N=128)$, aged $18-35$ years, were recruited through notices placed in community and university newspapers and bulletin boards. Potential participants underwent a telephone screening interview and a structured clinical interview, and completed a psychiatric symptom checklist (SCL-90; Derogatis, 1983), the Michigan Alcoholism Screening Test (Selzer, 1971). All participants received a screening electrocardiogram and physical examination. Exclusion criteria were any current medical condition requiring medication, use of prescription drugs (including birth control pill) in the previous 6 months, medical conditions for which amphetamine is contraindicated (eg diabetes, asthma, glaucoma, hypertension, epilepsy, migraine), any Axis I disorder other than nicotine dependence (APA, 1994), drug allergies (except antibiotics), endocrine disorders, a history of psychosis, total abstention from all drugs including alcohol, and, in women, a history of menstrual irregularities or current or intended pregnancy or lactation. Individuals with less than a high school education, lack of fluency in English, or night shift work were also excluded.

Before the first session, subjects provided their informed consent. Subjects were told that the purpose of the study 
was to study the effects of drugs on behavior. For blinding purposes, the consent form listed drugs other than those that would be administered (eg stimulant, sedative, antihistamine, hormone, and placebo). In the consent form, participants agreed not to take any drugs other than their usual amounts of caffeine and nicotine for $24 \mathrm{~h}$ before and $24 \mathrm{~h}$ following each session. The study was approved by the Institutional Review Board at The University of Chicago in accordance with the Code of Federal Regulations (Title 45, Part 46) 'Protection of Human Subjects' adopted by the National Institutes of Health and the Office for Protection from Research Risks. The study was conducted ethically in accordance with the Helsinki Declaration of 1964 (revised 1989) and the National Advisory Council on Drug Abuse Recommended Guidelines for the Administration of Drugs to Human Subjects.

\section{Procedure}

Participants took part in a three-session, within-subjects, placebo-controlled crossover study investigating the moodaltering effects of two doses of $d$-amphetamine (10 and $20 \mathrm{mg}$ ) and placebo. Sessions were separated by at least $48 \mathrm{~h}$, and women were tested only during the follicular phase of the menstrual cycle (days 2-14; White et al, 2002). Subjects were instructed to consume a light breakfast (bagel, no dairy, no acidic juices) $1 \mathrm{~h}$ prior to their test session, to standardize drug absorption.

Sessions were conducted from 0900 to 1345 . Upon arrival at the laboratory, subjects provided urine and breath samples to confirm abstinence from alcohol and drugs, and women were tested for pregnancy. Urine samples were tested for $d$-amphetamine, cocaine, PCP, opiate, and marijuana use with Ontrak TesTstik ${ }^{\mathrm{TM}}$ test kits (Roche Diagnostic Systems Inc., Somerville, NJ). Breath alcohol level was assessed using an Alco-Sensor III hand-held Breathalyzer (Intoximeters Inc., St Louis, MO). No participant tested positive for drug use or pregnancy.

At 0915, baseline (pre-capsule) measures of heart rate and systolic and diastolic blood pressure were obtained, and subjects completed self-report mood and drug effects questionnaires (see below). At 0930, participants ingested opaque capsules containing either $d$-amphetamine (10 or $20 \mathrm{mg}$ ) or placebo with $100 \mathrm{ml}$ of water. The drugs were administered in randomized order, under double-blind conditions. At 1000 and every 30 min until 1330, subjects completed self-report questionnaires and physiological measures were obtained. Subjects were permitted to leave the laboratory at 1345. After all three sessions were completed, a debriefing interview was conducted to explain the study and pay the subjects.

Prior to study participation, subjects completed personality measures (see below), selected to assess traits of reward sensitivity, fearlessness, and impulsivity.

\section{Drugs}

$d$-Amphetamine tablets ( $5 \mathrm{mg}$; Dexedrine $\left.{ }^{\circledR}\right)$ were placed in opaque, colored gelatin capsules (size 00) with dextrose filler. Placebo capsules contained only dextrose. The doses of $d$-amphetamine (10 and $20 \mathrm{mg}$ ) were selected because they reliably increase subjective measures of stimulant effects (Martin et al, 1971; Foltin and Fischman, 1991).

\section{Dependent Measures}

Subjective states assessment. Subjective and mood-altering effects of $d$-amphetamine were determined using the Addiction Research Center Inventory (ARCI; Martin et al, 1971), a visual analogue Drug Effects Questionnaire (DEQ), and a visual analogue adjective checklist (VAS), and an experimental version of the Profile of Mood States (POMS; McNair et al, 1971). The 49-item ARCI is a true-false questionnaire with five empirically derived scales sensitive to certain drugs or groups of drugs: A (AMPH-like, stimulant effects), BG (Benzedrine Group, energy and intellectual efficiency), MBG (Morphine-Benzedrine Group, euphoric effects), LSD (Lysergic Acid Diethylamide, dysphoric effects, somatic complaints), and PCAG (Pentobarbital-Chlorpromazine-Alcohol Group, sedative effects) (Martin et al, 1971; Fischman and Foltin, 1991). The DEQ is a locally developed visual analogue questionnaire that assesses the extent to which participants experience four subjective states: 'Feel Drug', 'Feel High', 'Like Drug', and 'Want More'. It is sensitive to several psychoactive drugs, including stimulants (Fischman and Foltin, 1991; Justice and de Wit, 2000a,b). The POMS consists of 72 adjectives commonly used to describe momentary mood states. Participants indicate how they feel at that moment in relation to each of the adjectives on a 5-point scale ranging from 'not at all' (0) to 'extremely' (4). The ARCI, DEQ, and POMS measures were chosen for analysis below as multiple measures of self-reported drug effects and subjective mood.

\section{Independent Measures}

Personality. Personality traits were assessed through MPQBF (Patrick et al, 2002). The MPQ consists of three superfactors, labeled Constraint, Positive Emotionality, and Negative Emotionality. Each superfactor consists primarily of three or four lower-order scales: Constraint consists primarily of Harm Avoidance, Control, and Traditionalism; Positive Emotionality consists primarily of Social Potency, Achievement, Social Closeness, and WellBeing; and Negative Emotionality consists primarily of Stress Reaction, Alienation, and Aggression (Patrick et al, 2002; Tellegen, 1982; Tellegen and Waller, in press). The brief form used in this study is strongly correlated with the long form of this questionnaire (Tellegen, 1982; Patrick et al, 2002). Four MPQ-BF scales were chosen a priori as measures of interest for the current study: the Agentic Positive Emotionality factor and the Social Potency scale, which measure reward sensitivity; the Harm Avoidance scale, which measures physical fear $v s$ fearlessness; and the Control scale, which measures planfulness $v s$ behavioral spontaneity. Three additional scales were included to test the discriminant validity of the above personality measures: Social Closeness, which measures affiliation rather than reward sensitivity; Stress Reaction, which measures anxiety proneness rather than physical fear; and Absorption, which measures the tendency to experience mental states vividly and quickly, providing an index of the spontaneity of mental state rather than behavior. 


\section{Data Analysis}

First, we conducted a preliminary analysis of variance using all the participants to characterize the effects of amphetamine. A summary, area under the curve (AVC) measure was derived to characterize each subject's response to the drug, using the post post-capsule measures, and subtracting the pre-drug baseline score. Separate one-way ANOVAs (drug: placebo, $10 \mathrm{mg}, 20 \mathrm{mg}$ amphetamine) were conducted for each of the 19 dependent measures (Table 2). Least significant difference post hoc comparisons were conducted to determine which conditions differed. To reduce the data into a smaller number of higher-order drug effect factors more appropriate for analysis with personality, outcomes showing significant drug effects (Table 2) were entered into a principal components analysis (promax rotation; $N=128$ ). Factor analyses were conducted separately for the two doses in order to determine whether the factor structure would replicate across doses. Based on examination of the scree plots, factors with eigenvalues greater than 2.0 were extracted and explained $50-60 \%$ of the variance in drug effects at each dose. Scores for each extracted factor were calculated as follows. $Z$-scores were calculated for area under the curve summary values for each drug outcome item, and Drug Effect factor scores were then calculated as the average $Z$-score of those scales uniquely loading $(>0.5)$ on each factor, with no cross-loadings greater than 0.5 on the alternate factor (see Table 4 for details). The factors resulting from this principal components analysis formed the basis of the subsequent analyses examining relations between drug responses and personality.

Second, we examined relationships between the different personality measures, in order to determine whether the measures were independent in the current sample $(N=128)$. Pearson's product-moment correlations (twotailed) were conducted between MPQ-BF measures of reward sensitivity (Agentic Positive Emotionality, Social Potency), physical fearlessness (Harm Avoidance), impulsivity (Control), and the three discriminant validity measures (Social Closeness, Stress Reaction, Absorption).

Third, we examined relationships between baseline (predrug) mood ratings on the study days and personality to determine whether the groups based on personality differed in mood states in the absence of drug. The pre-capsule mood ratings from the three experimental sessions were averaged for each subject. To be consistent with planned amphetamine analyses (see above), these means were transformed into standard scores ( $Z$-scores) and data were reduced to an average of the POMS scales loading $>0.5$ on drug factor 1 (Positive Activation) (see Table 4). For each MPQ-BF trait, subjects were rank-ordered based on their scores on the specific personality scale indexing that trait (see Table 4), and individuals with scores in the lowest and highest third of the sample distribution on each trait

Table 2 F Values (ANOVA) for Drug Effects, Area Under the Curve (I0 mg Amphetamine, 20 mg Amphetamine, or Placebo; N= I 28)

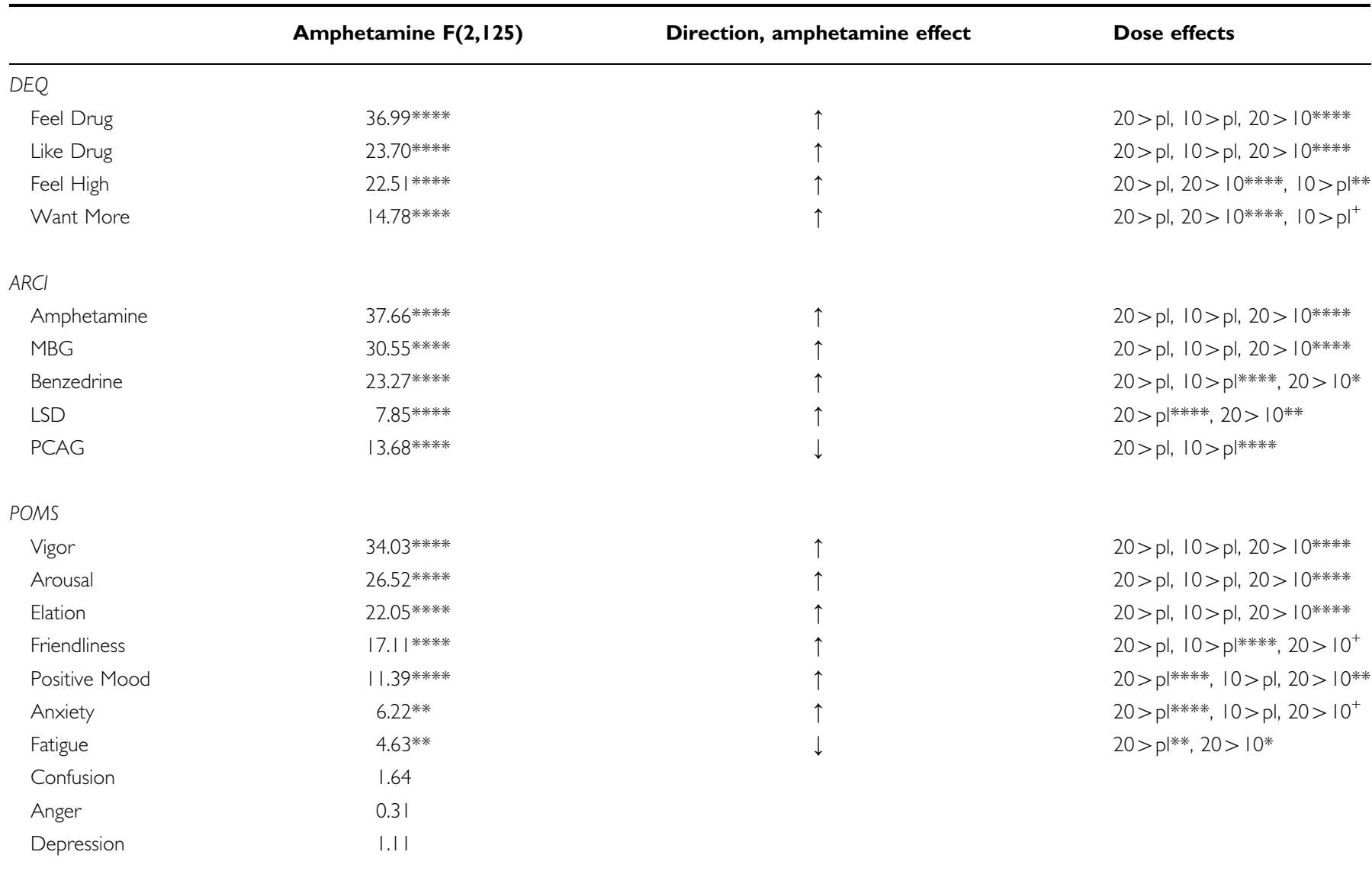

Subjective responses were assessed through the empirically derived ARCl scales, the POMS scales, and DEQ items. ${ }^{+} p \leqslant 0.10 ; * p \leqslant 0.05 ; * * p \leqslant 0.01 ; * * * * p \leqslant 0.001$. 
measure $(N=43$ in each group; total $N=86)$ were compared using one-way, between-subjects ANOVA.

Fourth, to address our primary goal, we examined subjective responses to amphetamine in relation to scores on the MPQ-BF. The drug effect factor scores (calculated above; ie Positive Activation; Feel/Somatic Effects) were assessed for personality effects using a series of ANCOVA models. Findings were corrected for multiple comparisons via Bonferroni correction. As described above, an extreme groups approach, rather than the full sample, was chosen to identify potentially vulnerable subsamples of healthy populations, and the lowest and highest third of the participants on each personality trait $(N=43$ in each group; total $N=86$ ) were compared. Responses on the placebo session were entered as covariates to control for expectancy effects. Potential interactions between personality traits were assessed post hoc, using multivariate linear models for drug effect outcomes related to more than one personality measure. The significance level for all statistical tests was set at $p<0.05$ (two-tailed).

Finally, several manipulation checks were conducted to assess order effects and beliefs regarding the drug classes received on each day of the study. Order effects were assessed by coding the order of amphetamine administration for each participant (placebo-first, $10 \mathrm{mg}$-first, $20 \mathrm{mg}$ first), and were included in drug effects ANCOVA models for outcomes with significant personality effects. To assess the effectiveness of the blinding, subjects indicated whether they believed they had received a stimulant, a sedative/ tranquilizer, alcohol, or a placebo after each session. These results were compared across the drug conditions using $\chi^{2}$ tests.

\section{RESULTS}

\section{Sample Characteristics}

Participants in the full sample $(N=128 ; 64$ women $)$ were ethnically diverse (54\% Caucasian, 22\% African American, 13\% Asian, 9\% Latino, 1\% Native American), in their early 20s (age 23.6 \pm 4.1 years), well educated $(15.1 \pm 1.6$ years education), and had BMIs in the normal range $(\mathrm{BMI}=$ $22.6 \pm 2.3 \mathrm{~kg} / \mathrm{m}^{2}$; men: $73.9 \pm 10.1 \mathrm{~kg}$; women: $62.2 \pm 8.5 \mathrm{~kg}$ ). Participants reported a range of current recreational substance use (alcohol: $4.2 \pm 3.6$ drinks/week; caffeine: $1.2 \pm 1.3$ cups/day; marijuana: $0.9 \pm 2.7$ times/month; cigarettes:
$0.8 \pm 2.2$ cigarettes/week) and lifetime recreational substance use (\% ever used: stimulants $14.8 \%$; sedatives $5.5 \%$; opiates $12.5 \%$; hallucinogens $32 \%$; marijuana $57 \%$; inhalants $10.9 \%)$.

\section{Personality}

All participants $(N=128)$ had valid scores on the MPQ-BF. Mean scores on the scales (Social Potency, Absorption, Harm Avoidance, and Stress Reaction) were within the range of previously published scores (Patrick et al, 2002). Pearson correlations and descriptive statistics for the seven MPQ-BF scales are presented in Table 3.

We examined the relationships between different personality subscales in the full sample of 128 subjects. Table 3 indicates that the reward sensitivity scales (Agentic Positive Emotionality, Social Potency) were highly inter-related $(r=0.65)$ and were independent of the physical fearlessness scale (Harm Avoidance) and the impulsivity scale (Control). Thus, the ability to measure reward sensitivity as separate from fearlessness or impulsivity appears to be good in the current sample. Harm Avoidance and Control were moderately correlated $(r=0.4)$. The discriminant scales appeared to be independent of the larger traits: Social Closeness was not related to Agentic Positive Emotionality $(r=0.09)$; Stress Reaction was not related to Harm Avoidance $(r=-0.05)$; and Absorption was weakly associated with Control $(r=-0.22)$.

\section{Drug Effects and Drug Effect Factors}

Amphetamine produced its expected effects on the DEQ, ARCI, and POMS measures, and most effects were dose dependent (see Table 2). Individual outcome scales showing significant drug effects (Table 2) were entered into a principal components analysis (promax rotation) for each dose. Factor loadings for each drug outcome scale appear in Table 4. As seen in Table 4, factor structure of drug responses at the 10 and $20 \mathrm{mg}$ doses was similar, with the exception of DEQ Like Drug and DEQ Want More Drug, which loaded on the positive rather than the somatic factor in response to the $20 \mathrm{mg}$ dose. Based on the common pattern of factor loadings across doses, Factors 1 and 2 have been labeled as Positive Activation and Feel/Somatic drug effects, respectively (see Table 4).

Table 3 MPQ-BF Personality Scores Intercorrelation Matrix and Descriptive Statistics (Pearson Correlations, Raw MPQ-BF Scores, $N=128)$

\begin{tabular}{|c|c|c|c|c|c|c|c|c|c|}
\hline & $\mathbf{I}$ & 2 & 3 & 4 & 5 & 6 & 7 & $\mathbf{M}$ & SD \\
\hline I Agentic Positive Emotionality & 1.00 & & & & & & & 64.9 & 12.5 \\
\hline 2 Social Potency & $0.65 * * * * * *$ & 1.00 & & & & & & 7.2 & 3.2 \\
\hline 4 Control & 0.12 & -0.13 & 0.40 ******** & 1.00 & & & & 8.1 & 3.0 \\
\hline 5 Social Closeness & 0.09 n.s. & $0.23 * * *$ & 0.05 & -0.07 & 1.00 & & & 7.8 & 3.1 \\
\hline
\end{tabular}

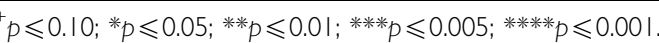


Table 4 Principal Components Analysis, AUC Drug Effects $(N=128)$

\begin{tabular}{|c|c|c|c|c|}
\hline \multirow[b]{3}{*}{ Drug effect scales } & \multicolumn{2}{|r|}{$10 \mathrm{mg}$} & \multicolumn{2}{|r|}{$20 \mathrm{mg}$} \\
\hline & Factor I & Factor 2 & Factor I & Factor 2 \\
\hline & Positive & Feel/Somatic & Positive & Feel/ Somatic \\
\hline DEQ Feel & 0.17 & 0.77 & 0.37 & 0.85 \\
\hline DEQ Like Drug & 0.47 & $0.5 I$ & 0.72 & 0.37 \\
\hline DEQ High & 0.36 & 0.76 & 0.54 & 0.82 \\
\hline DEQ More & 0.22 & 0.54 & 0.62 & 0.35 \\
\hline $\mathrm{ARCI} L S D$ & -0.21 & 0.61 & -0.13 & 0.65 \\
\hline $\mathrm{ARCl} A$ & 0.49 & $0.5 I$ & 0.66 & 0.52 \\
\hline $\mathrm{ARCl} B G$ & 0.67 & 0.34 & 0.8 & 0.25 \\
\hline $\mathrm{ARCI} M B G$ & 0.62 & 0.37 & 0.69 & 0.48 \\
\hline ARCI PCAG ${ }^{a}$ & -0.64 & -0.22 & -0.68 & 0.19 \\
\hline POMS Vigor & 0.84 & 0.29 & 0.88 & 0.17 \\
\hline POMS Arousal & $0.8 I$ & 0.32 & 0.82 & 0.16 \\
\hline POMS Elation & 0.82 & 0.08 & 0.86 & 0.17 \\
\hline POMS Friendly & 0.66 & -0.12 & 0.76 & 0.07 \\
\hline POMS Positive Mood & 0.84 & 0.02 & 0.85 & 0.06 \\
\hline POMS Fatigue $^{\mathrm{a}}$ & -0.59 & -0.05 & -0.57 & 0.08 \\
\hline POMS Anxiety & -0.04 & 0.41 & -0.2 & 0.45 \\
\hline
\end{tabular}

a Outcome inversely related to amphetamine; see Table 3.

Items loading $>0.5$ that were not cross-loaded on the alternate factor and that were entered into calculation of drug effect factor scores used in the personality analysis are in bold italics.

\section{Pre-Drug Differences}

Several MPQ scales were associated with basal mood states (ie prior to the ingestion of the capsules; Table 5). Participants who scored high on personality measures of Agentic Positive Emotionality, Control, and Social Closeness and who scored low on Stress Reaction had higher basal scores on POMS measures from the Positive Activation factor (POMS Vigor, Arousal, Elation, Friendliness, and Positive Mood and low Fatigue) compared to those with opposite scores on these traits. The results with Control remained significant after Bonferroni correction $(p<0.005)$. The directions of these baseline associations are consistent with those previously reported (Tellegen, 1985; Watson and Clark, 1984; Watson et al, 1992). However, it is notable that most of the significant associations between personality and the pre-drug mood states were with personality traits that were not related to self-reported mood effects after consumption of the capsules (see below).

\section{Drug Effect Factors Related to Personality}

Several MPQ scales were associated with the effects of amphetamine on the Positive Activational drug effects factor (Table 5). Associations between personality and positive drug factor are described below.

Associations with trait reward sensitivity. Participants who scored high on the MPQ-BF measure of Social Potency reported marginally greater levels of positive drug effects in
Table 5 Personality, Basal Mood and Higher-Order Drug Effects: Differences between Outer Thirds Personality Groups $(N=86)$

\begin{tabular}{|c|c|c|c|c|}
\hline & \multicolumn{2}{|c|}{ Basal mood } & \multicolumn{2}{|c|}{ Drug effects } \\
\hline & Positive & Direction & Positive & Direction/dose \\
\hline \multicolumn{5}{|l|}{ Reward sensitivity } \\
\hline $\begin{array}{l}\text { I. Agentic Positive } \\
\text { Emotionality }\end{array}$ & $5.46 *$ & $\mathrm{H}$ & & \\
\hline 2. Social Potency & & & $2.89^{+}$ & $\mathrm{H} / 20 \mathrm{mg}$ \\
\hline \multicolumn{5}{|l|}{ Fearlessness } \\
\hline 3. Harm Avoidance & & & $8.35 * * * *$ & ᄂ/O mg \\
\hline \multicolumn{5}{|l|}{ Impulsivity } \\
\hline 4. Control & $8.8 * * * *$ & $\mathrm{H}$ & & \\
\hline \multicolumn{5}{|l|}{ Discriminant validity } \\
\hline 5. Social Closeness & $3.66^{+}$ & $\mathrm{H}$ & & \\
\hline 6. Stress Reaction & $5.56 *$ & $\mathrm{~L}$ & & \\
\hline \multirow[t]{2}{*}{ 7. Absorption } & & & $3.07^{+}$ & $\mathrm{H} / 20 \mathrm{mg}$ \\
\hline & & & 3.95* & $\mathrm{H} / \mathrm{IO} \mathrm{mg}$ \\
\hline
\end{tabular}

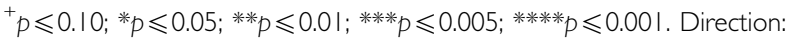
Significant elevation in outcome factors observed in: $L=$ lowest personality score group $(N=43) ; H=$ highest personality score group $(N=43)$ on indicated personality scale. Basal mood: ANOVA $(N=86)$ between outer thirds of ranked MPQ-BF personality scores, $F(1,84)$. Drug effects: ANCOVA on AUC drug effects $(N=86)$ between outer thirds of ranked personality scores, controlling for factor scores on placebo session, $F(I, 83)$. Somatic drug effects were not significantly related to MPQ-BF personality (n.s.), data not shown.

response to the $20 \mathrm{mg} d$-amphetamine dose than did participants with low scores on this scale $(p \leqslant 0.10)$. These data suggest a weak association between trait reward sensitivity and the positive activational effects of the $20 \mathrm{mg}$ dose.

Associations with trait physical fearlessness. Participants who scored low on Harm Avoidance reported greater levels of positive drug effects after $10 \mathrm{mg} d$-amphetamine than those with high scores. The association remained significant after Bonferroni correction $(p \leqslant 0.005)$. This drug effect is presented in Figure 1 and indicates a significant association between trait physical fearlessness and the positive activation induced by low-dose $d$-amphetamine.

Associations with trait impulsivity. There were no significant associations with MPQ Control. These data indicate that trait impulsivity was not associated with $d$-amphetamine effects in the current sample.

Specificity of results. Three additional personality measures were included as potential discriminant tests of the specificity of relationships between amphetamine and the personality constructs of reward sensitivity, physical fearlessness, and behavioral impulsivity, as distinct from other personality constructs. These discriminant measures were Social Closeness (which measures affiliation rather than reward sensitivity), Stress Reaction (which measures 


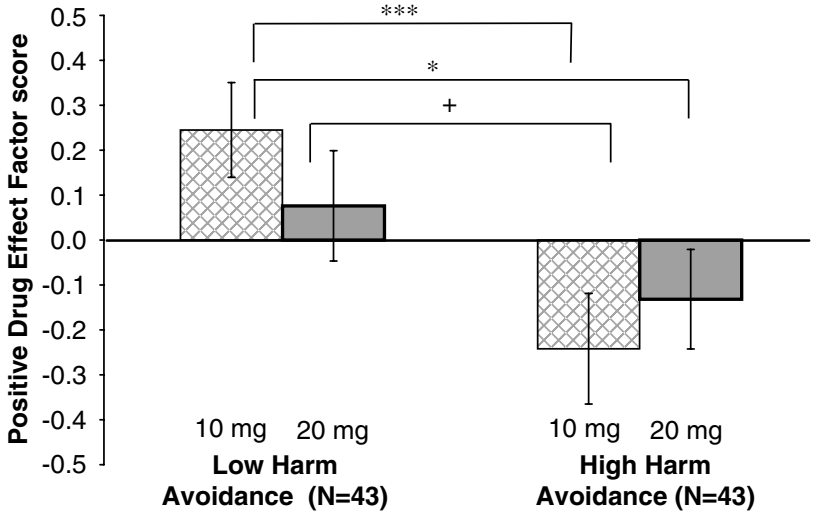

Figure I Trait physical fearlessness and positive activational responses to $d$-amphetamine. Higher-order positive drug effect (factor score) responses in participants with low and high scores on MPQ-BF Harm Avoidance; 10 and $20 \mathrm{mg}$ effects. ${ }^{*} p \leqslant 0.05 ;{ }^{*} * * * 0.005 ;{ }^{+} p \leqslant 0.10$.

anxiety rather than physical fear proneness), and Absorption (which measures the predisposition toward mental imagery and flexibility of emotional/cognitive set rather than behavioral impulsivity). Discriminant findings are separated below by a priori contrasts of interest. Reward sensitivity vs affiliation: Scores on Social Closeness were not related to $d$-amphetamine effects, in contrast with marginal findings with Social Potency (Table 5). This suggests that $d$ amphetamine effects could be specifically associated with individual differences in the trait of reward sensitivity, as distinct from the associated trait of affiliative extraversion. Physical fearlessness vs anxiety proneness: Scores on Stress Reaction were not related to $d$-amphetamine outcomes (Table 5). This suggests that associations with trait physical fearlessness are specific to this trait, and are not associated with the separate trait of anxiety proneness. Behavioral impulsivity vs mental imagery: Scores on Absorption were related to positive drug effects in response to both doses (see Figure 2). In contrast, scores on the Control scale, which measures behavioral impulsivity, were not related to $d$-amphetamine effects (Table 5). These data suggest that $d$ amphetamine effects on positive activation are more likely to relate to individual differences in the flexibility of mental/ emotional imagery (absorption) than to individual differences in behavioral impulsivity (low control).

Interactions. To assess whether individuals with extreme scores on two or more traits were at elevated risk for positive responses to $d$-amphetamine, personality interactions were assessed using multivariate linear models. A total of 56 participants had extreme scores on Absorption and one or more relevant traits (Harm Avoidance, Social Potency). The multivariate analysis indicated that interactions between personality traits were not significant $(p>0.50)$, and associations with Absorption remained marginally significant after controlling for scores on other traits (Positive factor effects: $10 \mathrm{mg}: \mathrm{F}(1,52)=2.6, p=0.11$; $20 \mathrm{mg}: \mathrm{F}(1,52)=3.5, p<0.10)$. Thus, in individuals with extreme scores on more than one relevant personality trait, having high scores on multiple traits (eg fearlessness and absorption) did not appear to increase self-reports of positive drug effects beyond that associated with a single

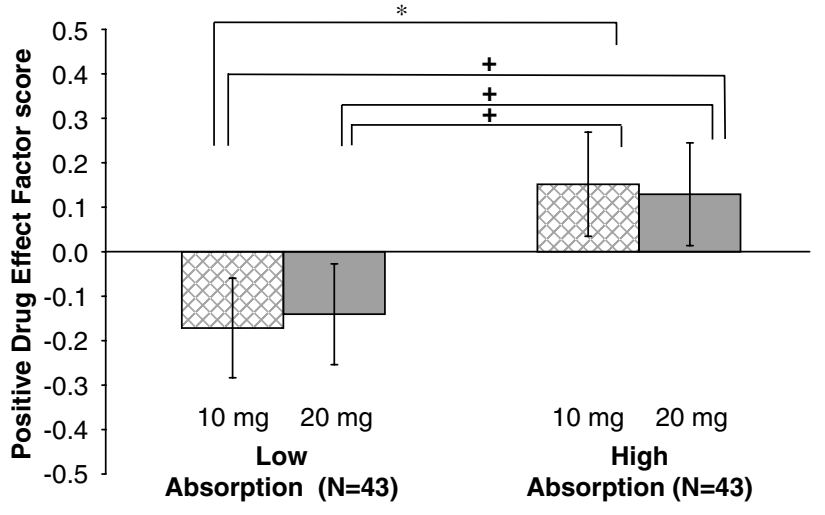

Figure 2 Trait Absorption and positive activational responses to $\mathrm{d}$-amphetamine. Higher-order positive drug effect (factor score) responses in participants with low and high scores on MPQ-BF Absorption; 10 and $20 \mathrm{mg}$ effects. ${ }^{*} p \leqslant 0.05 ;{ }^{+} p \leqslant 0.10$.

trait. This finding could reflect a true absence of interaction effects, or a ceiling effect on the psychometric self-report outcomes under study.

\section{Validity Checks}

Order effects. There were no significant effects of order or order by personality interactions for any outcome (n.s.).

Participant blindness. After $10 \mathrm{mg} d$-amphetamine, participants were equally likely to believe they received a stimulant $(N=38)$, sedative $(N=32)$, or placebo $(N=47$; $\chi^{2}=2.9$, n.s.), and after placebo, they were equally likely to believe they received either placebo $(N=53)$ or an active substance (sedative or stimulant; $N=64 ; \chi^{2}=1.03$, n.s.). After $20 \mathrm{mg} d$-amphetamine, they were more likely to report they had received a stimulant $(N=73)$ than a sedative or placebo $\left(N=49 ; \chi^{2}=4.7, p<0.05\right)$. These data indicate that participants were relatively blind to the study drug administered on the $10 \mathrm{mg}$ and placebo sessions.

\section{DISCUSSION}

The personality traits of reward sensitivity, physical fearlessness, and the tendency to experience mental states vividly and quickly were associated with a number of specific subjective responses to $d$-amphetamine in the current sample. There were three main findings. First, compared to individuals with high trait physical fear, individuals with low trait physical fear reported greater positive activational responses to low-dose $d$-amphetamine, showing greater energy, intellectual activation, euphoria, vigor, arousal, elation, friendliness, positive mood, and less fatigue and sedation (drug effects factor 1, Positive Activation) after the $10 \mathrm{mg}$ dose. These findings were the strongest of the study, and remained significant after correction for multiple comparisons. Second, individuals with high trait reward sensitivity had marginally greater positive responses as well as drug liking and drug wanting after the $20 \mathrm{mg}$ dose. Third, individuals with high mental imagery/flexibility had greater positive drug responses to 
both doses, and these effects were more significant at the lower (10 mg) dose. These findings are discussed in turn.

The first finding was that in healthy individuals with low scores on the trait measure of fear of physical danger (MPQBF Harm Avoidance), $10 \mathrm{mg} d$-amphetamine produced greater positive activational responses, that is, greater activation, euphoria, vigor, arousal, elation, friendliness, and positive mood, and less sedation and fatigue. Responses to amphetamine were unrelated to another negative emotional trait, Stress Reaction (Table 5), which measures anxiety proneness rather than trait fear (Tellegen, 1982; White and Depue, 1999). These findings indicate that individuals who are less fearful may be particularly vulnerable to the positive subjective effects of low doses of psychostimulants. In contrast, individuals who are high on Harm Avoidance may be protected from these activational effects.

The second finding was that $20 \mathrm{mg} d$-amphetamine produced greater activational drug effects, that is, greater energy, intellectual efficiency, euphoria, vigor, arousal, elation, friendliness, positive mood, lessened sedation and fatigue, and greater drug liking and drug wanting among individuals with high scores on a trait measure of reward sensitivity (MPQ-BF Social Potency). The effects of $20 \mathrm{mg} d$ amphetamine were not related to other personality measures, such as affiliative sociability (ie Social Closeness; see Table 5). The relationship between reward sensitivity and positive responses to $d$-amphetamine is consistent with the idea that a common neural mechanism, such as dopamine neurotransmission, mediates both trait reward sensitivity and subjective responses to a stimulant drug (Depue and Collins, 1999; Drevets et al, 2001). Although several previous studies failed to find an association between other measures of extraversion and amphetamine responses (eg Corr and Kumari, 2000; Chait, 1993; Uhlenhuth et al, 1981), the lack of effects in the previous studies could have been due to sample sizes or insensitivity of the extraversion measures used (see Depue and Collins, 1999; Lucas et al, 2000 for review).

The third finding was that subjects who scored high on trait mental imagery/flexibility (Absorption on the MPQ-BF) reported greater positive activational effects of $d$-amphetamine (10 and $20 \mathrm{mg}$ ). This relationship was significant at the $10 \mathrm{mg}$ dose and showed a trend toward greater positive drug effects as well as greater drug liking and drug wanting at the $20 \mathrm{mg}$ dose. In contrast, scores on the MPQ-BF measure of behavioral impulsivity (ie low Control) were unrelated to amphetamine effects. Our finding suggests that at both low and high doses, the personality trait of mental imagery and flexibility, but not behavioral impulsivity, may increase the vulnerability to positive, stimulant-like drug effects.

Overall, the present study had both strengths and weaknesses. Strengths included the use of an empirically derived personality instrument (MPQ-BF) with an orthogonal factor structure to assess temperament, multiple doses (10 and $20 \mathrm{mg}$ p.o.) of $d$-amphetamine, a placebo control, assessment of basal mood on study sessions, a double-blind administration of drugs, a manipulation check for participant blindness, and a large $(N=128)$ sample of men and women. Previous studies are less than half this size (within-subjects studies: eg $N=24$, Alessi et al, 2003;
$N=36$, Hutchison et al, 1999; $N=11$, Sax and Strakowski, 1998; $N=29$, Chait, 1993; $N=45$, Uhlenhuth et al, 1981; between-subjects studies: $N=20-22$ per group; see Corr and Kumari, 2000). Most significant associations between personality and the pre-drug, basal mood states were as expected for different personality groups, and were for outcomes that were not related to personality after consumption of the capsules (see Table 5). A limitation of the present study was that the sample consisted of a relatively homogeneous subject population, who were in a narrow age range (18-35 years), educated (all had completed high school and many had higher degrees), and who were physically and psychiatrically healthy. The relationships between personality and drug effects might be different in a more heterogeneous population sample including, for example, older individuals, drug users, and individuals with psychiatric disorders.

In toto, the current data indicate that the subjective effects of amphetamine vary as a function of specific personality traits in healthy volunteers. Lack of fear of physical danger, sensitivity to reward, and the tendency to experience internal emotional states vividly and quickly were associated with differences in the magnitude of amphetamine-induced energy, intellectual efficiency, euphoria, vigor, arousal, elation, friendliness, positive mood, lessened sedation and fatigue and, in response to the higher dose, greater drug liking and drug wanting. Notably, the effect of personality was most significant for the $10 \mathrm{mg}$ dose, suggesting that individual differences in reactivity to the drug may be more readily detected at low doses. At the $10 \mathrm{mg}$ dose, a substantial number of subjects were unable to guess the drug class they had received, whereas at the $20 \mathrm{mg}$ dose, the pharmacological drug effects may override subtle individual differences. The results support the idea that certain personality traits relate to endogenous, betweensubjects variations in the modulation of monoamine systems in humans, which can impact responses to stimulant drugs such as $d$-amphetamine that act on these systems. The results form the basis for future studies of the specific neurobiological mechanisms that may be involved in the vulnerability to psychostimulants in otherwise healthy individuals.

\section{ACKNOWLEDGEMENTS}

We thank Jen McDonald, Vandana Grover, Michelle Dassinger, Justin Enggasser, Liz Heinz, and Clare Tessman of the Human Behavioral Pharmacology Laboratory and Dr Christopher Kahler of Brown University for their assistance. This research was supported by USPHS Grant DA09133 and training Grant T32 DA07255 and GCRC MO1 RR00055.

\section{REFERENCES}

Acton GS (2003). Measurement of impulsivity in a hierarchical model of personality traits: implications for substance use. Subst Use Misuse 38: 67-83.

Alessi SM, Greenwald M, Johanson CE (2003). The prediction of individual differences in response to D-amphetamine in healthy adults. Behav Pharmacol 14: 19-32. 
American Psychiatric Association (1994). Diagnostic and Statistical Manual of Mental Disorders: DSM-IV, 4th edn. APA: Washington, DC.

Bass B (1956). Development and evaluation of a scale for measuring social acquiescence. J Abnorm Soc Psychol 53: 296-299.

Campbell JB, Heller JF (1987). Correlations of extraversion, impulsivity and sociability with sensation seeking and MBTIintroversion. Pers Indiv Differ 8: 133-136.

Chait LD (1993). Factors influencing the reinforcing and subjective effects of $d$-amphetamine in humans. Behav Pharmacol 4: 191-199.

Cloninger CR (1986). A unified biosocial theory of personality and its role in the development of anxiety states. Psychiatr Dev 4: 167-226.

Cloninger CR (1989). The Tridimensional Personality Questionnaire. Department of Psychiatry and Genetics, Washington University School of Medicine.

Coccaro EF, Kavoussi RJ, Trestman RL, Gabriel SM, Cooper TB, Siever LJ (1997). Serotonin function in human subjects: intercorrelations among central 5-HT indices and aggressiveness. Psychiatry Res 73: 1-14.

Corr PJ, Kumari V (2000). Individual differences in mood reactions to $d$-amphetamine: a test of three personality factors. J Psychopharmacol 14: 371-377.

Crabbe JC, Jarvik LF, Liston EH, Jenden DJ (1983). Behavioral responses to amphetamines in identical twins. Acta Genet Med Gemellol (Roma) 32: 139-149.

de Wit H, Uhlenhuth $\mathrm{EH}$, Johanson CE (1986). Individual differences in the reinforcing and subjective effects of amphetamine and diazepam. Drug Alcohol Depend 16: 341-360.

Depue RA, Collins PF (1999). Neurobiology of the structure of personality: dopamine, facilitation of incentive motivation, and extraversion. Behav Brain Sci 22: 491-569.

Depue RA, Luciana M, Arbisi P, Collins P, Leon A (1994). Dopamine and the structure of personality: relation of agonistinduced dopamine activity to positive emotionality. J Pers Soc Psychol 67: 485-498.

Derogatis L (1983). SCL-90-R Manual-II. Clinical Psychometric Research: Towson.

Drevets WC, Gautier C, Price JC, Kupfer DJ, Kinahan PE, Grace AA et al (2001). Amphetamine-induced dopamine release in human ventral striatum correlates with euphoria. Biol Psychiatry 49: 81-96.

Eysenck HJ, Eysenck SBG (1968). Eysenck Personality Inventory (Manual). Educational and Industrial Testing Service: San Diego.

Eysenck HJ, Eysenck SBG (1975). Manual of the Eysenck Personality Questionnaire (Adults). Hodder and Stoughton: London.

Fischman MW, Foltin RW (1991). Utility of subjective-effects measurements in assessing abuse liability of drugs in humans. Br J Addict 86: 1563-1570.

Foltin RW, Fischman MW (1991). Assessment of abuse liability of stimulant drugs in humans: a methodological survey. Drug Alcohol Depend 28: 3-48.

Glicksohn J, Abulafia J (1998). Embedding sensation seeking within the big three. Pers Indiv Differ 25: 1085-1099.

Goldstein RZ, Volkow ND, Chang L, Wang GJ, Fowler JS, Depue RA et al (2002). The orbitofrontal cortex in methamphetamine addiction: involvement in fear. Neuroreport 13: 2253-2257.

Goodstadt MS, Cook G, Magid S, Gruson V (1978). The drug attitudes scale (DAS): its development and evaluation. Int $J$ Addict 13: 1307-1317.

Haertzen CA, Martin WR, Ross FE, Neidert GL (1980). Psychopathic State Inventory (PSI): development of a short test for measuring psychopathic states. Int J Addict 15: 137-146.
Hutchison KE, Wood MD, Swift R (1999). Personality factors moderate subjective and psychophysiological responses to $d$-amphetamine in humans. Exp Clin Psychopharmacol 7: 493-501.

Jackson DN (1974). Personality Research Form (Manual). Research Psychologists: Goshen.

Justice A, de Wit H (2000a). Acute effects of estradiol pretreatment on response to D-amphetamine in women. Neuroendocrinology 71: 51-59.

Justice AJH, de Wit H (2000b). Acute effects of D-amphetamine during the early and late follicular phases of the menstrual cycle in women. Pharmacol Biochem Behav 66: 509-515.

Lucas RE, Diener E, Grob A, Suh EM, Shao L (2000). Cross-cultural evidence for the fundamental features of extraversion. J Pers Soc Psychol 79: 452-468.

Martin WR, Sloan JD, Sapira JD, Jasinski DR (1971). Physiologic, subjective, and behavioral effects of amphetamine, methamphetamine, ephedrine, phenmetrazine, and methylphenidate in man. Clin Pharmacol Ther 12: 245-258.

Mattay VS, Goldberg TE, Fera F, Hariri AR, Tessitore A, Egan MF et al (2003). Catechol $O$-methyltransferase val158-met genotype and individual variation in the brain response to amphetamine. Proc Natl Acad Sci USA 100: 6186-6191.

McNair D, Lorr M, Droppleman L (1971). Profile of Mood States. Educational and Industrial Testing Service: San Diego.

Morrone-Strupinsky JV (2002). Dopamine-facilitated contextincentive motivational binding as a function of extraversion. Dissert Abstr Int 62: 3411.

Nurnberger Jr JI, Gershon ES, Simmons S, Ebert M, Kessler LR, Dibble ED et al (1982). Behavioral, biochemical and neuroendocrine responses to amphetamine in normal twins and 'well-state' bipolar patients. Psychoneuroendocrinology 7: 163-176.

Patrick CJ, Curtin JJ, Tellegen A (2002). Development and validation of a brief form of the Multidimensional Personality Questionnaire. Psychol Assess 14: 150-163.

Reif A, Lesch K-P (2003). Toward a molecular architecture of personality. Behav Brain Res 139: 1-20.

Reist C, Helmeste D, Albers L, Chhay H, Tang SW (1996). Serotonin indices and impulsivity in normal volunteers. Psychiatry Res 60: 177-184.

Rotter JB (1966). Generalized expectancies for internal versus external control of reinforcement. Psychol Monogr 80: 1-28.

Sax KW, Strakowski SM (1998). Enhanced behavioral response to repeated $d$-amphetamine and personality traits in humans. Biol Psychiatry 44: 1192-1195.

Selzer ML (1971). The Michigan alcoholism screening test: the quest for a new diagnostic instrument. Am J Psychiatry 127: $1653-1658$.

Silberman EK, Reus VI, Jimerson DC, Lynott AM, Post RM (1981). Heterogeneity of amphetamine response in depressed patients. Am J Psychiatry 138: 1302-1307.

Smith CS, Reilly C, Midkiff K (1989). Evaluation of three circadian rhythm questionnaires with suggestions for an improved measure of morningness. J Appl Psychol 74: 728-738.

Taylor JA (1953). A personality scale of manifest anxiety. J Abnorm Soc Psychol 48: 285-290.

Tellegen A (1982). Brief Manual for the Multidimensional Personality Questionnaire. Unpublished manuscript, University of Minnesota, Minneapolis.

Tellegen A (1985). Structures of mood and personality and their relevance to assessing anxiety, with an emphasis on self-report. In: Tuma AH, Maser JD (eds). Anxiety and the Anxiety Disorders. Erlbaum: Hillsdale, NJ. pp 681-706.

Tellegen A, Waller NG (in press). Exploring personality through test construction: development of the Multidimensional Personality Questionnaire. In: Briggs S, Cheek J (eds). Personality Measures: Development and Evaluation. JAI Press: Greenwich, CT. Vol 1. 
Uhlenhuth EH, Johanson CE, Kilgore K, Kobasa SC (1981). Drug preference and mood in humans: preference for $d$-amphetamine and subject characteristics. Psychopharmacology 74: 191-194.

Watson D, Clark LA (1984). Negative affectivity: the disposition to experience aversive emotional states. Psychol Bull 96: 465-490.

Watson D, Clark LA, McIntyre CW, Hamaker S (1992). Affect, personality, and social activity. J Pers Soc Psychol 63: 1011-1025.

White TL, Depue RA (1999). Differential association of traits of fear and anxiety with norepinephrine- and dark-induced pupil reactivity. J Pers Soc Psychol 77: 863-877.

White TL, Justice AJH, de Wit H (2002). Differential subjective effects of $d$-amphetamine by gender, hormone levels and menstrual cycle phase. Pharmacol Biochem Behav 73: 729-741.
Witkin HA, Oltman PK, Raskin E, Karp SA (1971). Embedded Figures Test (Manual). Consulting Psychologists Press: Palo Alto.

Zuckerman M (1971). Dimensions of sensation seeking. J Consult Clin Psychol 36: 45-52.

Zuckerman M (1989). Personality in the third dimension: a psychobiological approach. Pers Indiv Differ 10: 391-418.

Zuckerman M (1993). P-impulsive sensation seeking and its behavioral, psychophysiological biochemical correlates. Neuropsychobiology 28: 30-36.

Zuckerman M, Eysenck S, Eysenck HJ (1978). Sensation seeking in England and America: cross-cultural, age, and sex comparisons. J Consult Clin Psychol 46: 139-149. 